\title{
Investigating suspended-sediment transport in a shallow lake using a three-dimensional hydrodynamic and sediment model
}

\author{
Wen-Cheng Liu ${ }^{1}, *$, Hong-Ming Liu ${ }^{1}$ and Chin-Yu Chiu ${ }^{2}$ \\ ${ }^{1}$ Department of Civil and Disaster Prevention Engineering, National United University, Miaoli 36063, Taiwan. \\ ${ }^{2}$ Research Center for Biodiversity, Academia Sinica, Taipei 11529, Taiwan. \\ *Corresponding author.e-mail: wcliu@nuu.edu.tw
}

MS received 30 May 2017; revised 4 April 2018; accepted 8 May 2018;

published online 19 January 2019

A three-dimensional, unstructured-grid hydrodynamic and suspended-sediment transport model was developed to simulate the temporal and spatial variations of suspended sediment and was applied to the subtropical subalpine Tsuei-Feng Lake (TFL) of Taiwan. The model was validated with measured water level and suspended-sediment concentration in 2009, 2010 and 2011. The overall model simulation results are in quantitative agreement with the observational data. The validated model was then applied to explore the most important parameter that affects the suspended-sediment concentration and to investigate the effect of wind stress on the mean current and suspended-sediment distribution in this shallow lake. Modelling results of the sensitivity analysis revealed that the settling velocity is a crucial parameter and the erosion rate is less important in the suspended-sediment transport model. Remarkable lake circulation was found based on the strength of wind speed and wind direction. A strong wind would result in a higher mean current in the top layer and suspended-sediment distribution in the top and bottom layers. This study demonstrated that wind stress played a significant influence on mean circulation and suspended-sediment transport in a shallow lake.

Keywords. Suspended sediment; hydrodynamics; numerical model; wind-driven current; Tsuei-Feng Lake.

\section{Introduction}

Sediment has been identified as one of the important non-point source pollutants (Chao et al. 2007). Sediment-water interactions in shallow lakes may become enormously important with time, since bed sediments constituent the ultimate repository for nutrients and contaminants, and fine particles and nutrients in the sediment bed may repeatedly be recycled (Chao et al. 2008; Chalov et al. 2015). Nutrient-rich sediment layers in the lakes participate in chemical and biological processes and exchange mass within the water column. The sediment layers affect the nutrient cycles via the diffusive fluxes of nutrients from sediment and via sediment resuspension (Horne and Goldman 1994; DiToro 2001; Ji et al. 2002; Kessarkar et al. 2009; Ramakrishnan and Rajawat 2012). The resuspension of toxic bottom sediments is an ecological concern since toxic contaminants can accumulate in the biota and food web of a lake (Gbah et al. 2001). Suspended sediment can also reduce the light intensity under water and affect the growth of phytoplankton (James et al. 1997). 
The dynamic processes involved in suspendedsediment transport such as flocculation, deposition and erosion (resuspension) have been studied by many scientists (Krone 1962; Partheniades 1965; Mehta and Partheniades 1975; Thorn 1981; Matty et al. 1987; Burban et al. 1990; Ziegler and Nisbet 1995; Houwing and Rijn 1998; Li and Mehta 1998). The number of laboratory studies has improved our knowledge of the resuspension behaviour of finegrained material. However, transferring the results of laboratory experiments to field studies still has been problematic because of the complexities of real sediments and of natural flows.

Sediment transport models have been broadly developed and applied to investigate sediment dynamics in lakes including a one-dimensional model (Chung et al. 2009; Clarke et al. 2009; Filistovic et al. 2015), a vertical two-dimensional model (Hawley et al. 2009; Zouabi-Aloui and Gueddari 2014), a horizontal two-dimensional model (Lee et al. 2007; Stroud et al. 2009; Wang et al. 2015; Zhang et al. 2015) and quasi-three-dimensional (Lou et al. 2000) and three-dimensional models (Cardenas et al. 2005; Lee et al. 2005; Chao et al. 2008; Lv et al. 2013; Wang et al. 2013; Liu et al. 2016). The erosion and resuspension of bottom sediment from the active layers is one of the major sources of the total suspended sediment in the water column (Sanford 1992). To accurately simulate the suspended-sediment concentration in lakes, incorporating resuspension and deposition into the suspended-sediment transport model is essential. However, three-dimensional models are particularly appropriate in cases such as regions with complex bathymetries, the vertical gradients in water temperature and suspendedsediment concentration, and density currents in the lakes.

Recent advances in computational fluid dynamics and sediment transport model formulations enable the computation of flows and sediment fluxes in three dimensions. However, the spatial and temporal scales, and model processes must be carefully selected for a particular study to ensure that the model will solve the problem at hand and that computations can be carried out in the practical sense. In the present study, a threedimensional, unstructured-grid hydrodynamic and suspended-sediment transport models were developed and applied to simulate the hydrodynamics and sediment dynamics in the Tsuei-Feng Lake (TFL). The model simulation was validated against profiles of water level, and time-variation and spatial-variation suspended solids from 2009 to 2011. The validated model then was applied to explore the most sensitive parameter affecting the suspended-sediment concentration and the influence of wind stress on mean currents and sediment dynamics.

\section{Description of study site}

TFL is located between the Taiping Mountain and Dayuan Mountain in the north-central region of Taiwan (figure 1a). The indicated altitude is $1900 \mathrm{~m}$ above sea level. The area of the lake is approximately $20 \mathrm{ha}$. It is one of the largest mountain lakes in Taiwan. It is also the most popular focus in the Taipingshan National Forest Recreation Area.

The regulation of the water flow into TFL primarily results in extreme water level fluctuation, which severely affects the activity and succession of fauna and flora in the area. The average annual temperature is approximately $11.4^{\circ} \mathrm{C}$, and the annual precipitation is more than $3662 \mathrm{~mm}$. TFL is subjected to several typhoons in the summer and autumn each year, during which more than $1300 \mathrm{~mm}$ of precipitation may fall on the lake. The water column is stratified from early April to October. The water column is usually completely mixed in the winter and is associated with intensive rainfall during the typhoon season. The water quality variables of $\mathrm{pH}$, dissolved oxygen, total nitrogen and chlorophyll $a$ are in the range of 5.4-6.5, $5.9-7.7 \mathrm{mg} / \mathrm{l}, 0.5-1.4 \mathrm{mg} / \mathrm{l}$ and $0.4-6 \mu \mathrm{g} / \mathrm{l}$, respectively (Cheng 2010). The spatial distributions of suspended-sediment concentration on 6 June and 11 December 2010 are shown in figure 2. These indicate that the suspended-sediment concentration is higher on 11 December (during the autumn season) while it is lower on 6 June (during early summer). The suspended-sediment concentration in the lake exhibits temporal and spatial variations. According to a sieve analysis, the bottom sediment type can be classified in the range of fine sand and silt (Cheng 2010).

\section{Model description}

\subsection{Hydrodynamic model}

Multi-scale lake circulation modelling has become a mature field. The models used typically describe the free-surface elevation and velocities of various 

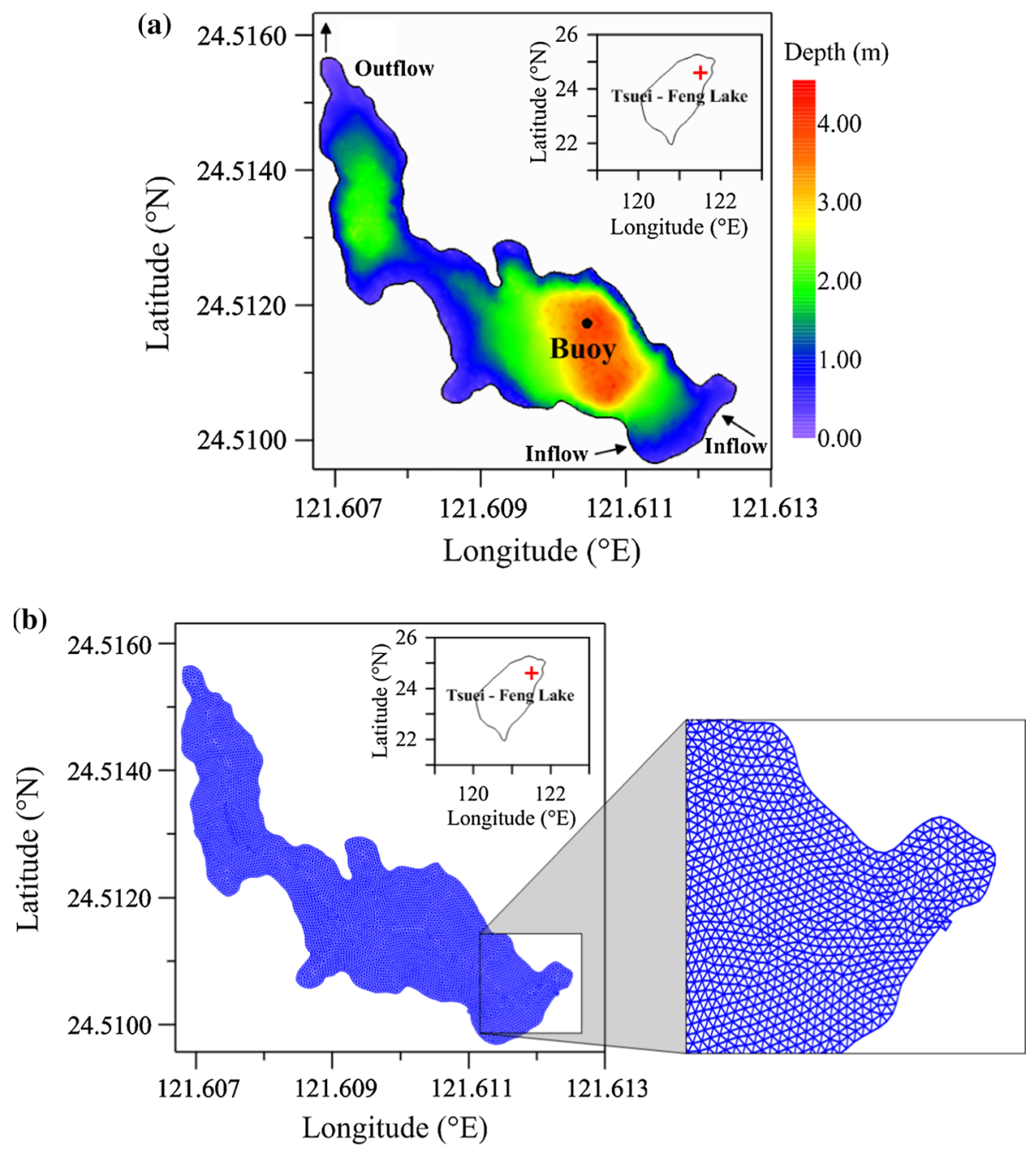

Figure 1. (a) Map of TFL in the north-centre region of Taiwan and (b) horizontal grid of TFL for three-dimensional hydrodynamic and suspended-sediment transport model. The grid size is approximately $5 \mathrm{~m}$.

water bodies by solving the Reynolds-averaged Navier-Stokes equations which represent the conservation of momentum subject to the hydrostatic and Boussinesq approximations. The transport equation of heat was used to solve the water temperature in water bodies. The equation of state describes water density as a function of water temperature. In the present study, the threedimensional, semi-implicit Eulerian-Lagrangian finite-element model (SELFE, Zhang and Baptista 2008) was adopted to simulate the hydrodynamic and hydrothermal characteristics in the TSF.

Numerical efficiency and accuracy consideration dictates the numerical formulation of SELFE. The SELFE solves the differential equation system with finite-element and finite-volume schemes. No mode splitting is used in SELFE, thus eliminating the errors associated with the splitting between the internal and external modes (Shchepetkin and Mcwilliam 2005). Semi-implicit schemes are adopted to all equations. The SELFE solves the governing equations with a key step of decoupling continuity and momentum equations via the bottom boundary. The SELFE handles the advection terms in the momentum equation with a EulerianLagrangian method, allowing larger time steps without compromising the computational stability and accuracy. For the advection terms in the transport equations (i.e., water temperature), either a Eulerian-Lagrangian scheme or a finite-volume upwind scheme is applied (Zhang and Baptista 2008).

In the SELFE, the horizontal domain is discretised with unstructured triangular grids. Along the vertical direction, a hybrid coordinate system 

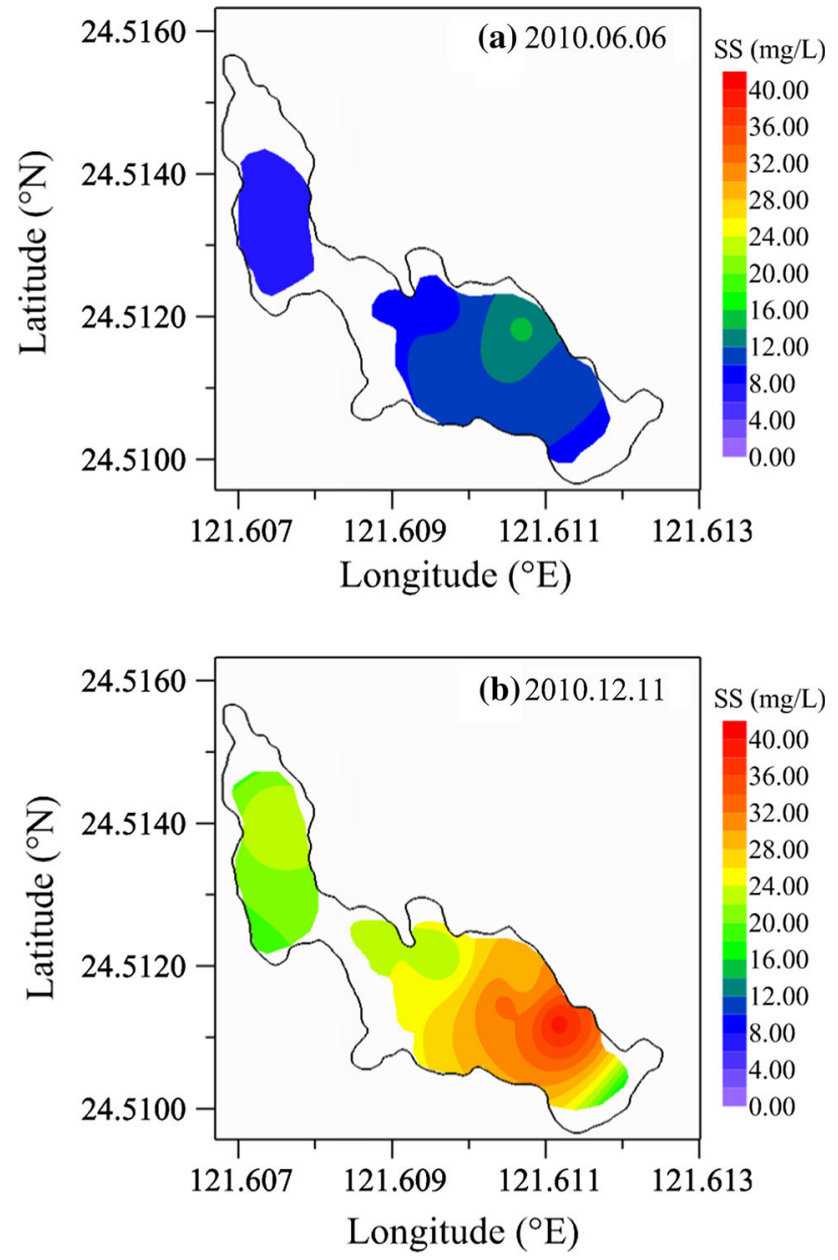

Figure 2. The spatial distribution of suspended-sediment concentration on (a) 6 June 2010 and (b) 11 December 2010. The white colour in the figure represents the dry area (no water).

consisting of the S-coordinate and Z-coordinate in the upper and deeper parts of the water column, respectively, can effectively prevent the so-called hydrostatic inconsistency issue. The interpolation at an arbitrary location in three-dimensional space is necessary for SELFE including the interpolation at the foot of the characteristic line and the conversion of velocity from element sides to nodes. The horizontal interpolation can be done in the transformed $S$ space in the regions where no $Z$ layers are used. This approach is more accurate in the shallow regions where rapid changes in bathymetry are common (Zhang and Baptista 2008).

After the domain is discretised horizontally and vertically, the basic three-dimensional units of SELFE are triangular prisms. In the original $Z$ space, the prisms may not have level bottom and top surfaces. A staggering scheme is used to define variables. The surface elevations are defined at the nodes. The horizontal velocities are defined at the side centres and whole levels. The vertical velocities are defined at the element centres and whole levels as they are solved with a finitevolume method. The linear shape functions are used for elevations and velocities. The locations, where temperatures are defined, depend on the methods used to solve the transport equations. They are defined at the prism centres if the finitevolume upwind method is used, and at both nodes and side centres, at whole levels, if the EulerianLagrangian method is used (Zhang and Baptista 2008). To generate meshes for numerical modelling, the SMS (Surface water Model System) software is adopted.

The detailed numerical formulation of SELFE including domain discretisation, barotropic module, baroclinic module and treatment of an explicit scheme can be found in the literature (Zhang and Baptista 2008).

To calculate the turbulent mixing processes, the SELFE uses the generic length scale turbulence closure of Umlauf and Buchard (2003), which has the advantage of encompassing most of the 2.5-equation closure $(K-\psi)$ model (Mellor and Yamada 1982; Rodi 1984; Wilcox 1998).

The vertical boundary conditions for the momentum equation play an important role in the SELFE numerical formulation to solve the unknown velocities. At the lake surface, the SELFE enforces the balance between the internal Reynolds stress and the applied shear stress can be expressed as:

$$
\nu \frac{\partial U}{\partial z}=\tau_{\mathrm{w}} \quad \text { at } z=\eta,
$$

where $z$ is the vertical coordinate, $U$ is the horizontal velocity with Cartesian components $(u, v), \nu$ is the vertical eddy viscosity, $\eta$ is the free-surface elevation and $\tau_{\mathrm{w}}$ is the wind stress which can be solved using the approach of Pond and Pickard (1998). The wind speed and direction were served as inputs to calculate the wind stress $\left(\tau_{\mathrm{w}}\right)$.

\subsection{Suspended-sediment transport model}

The suspended-sediment transport model is treated in two distinct models: the advection-diffusion components are based on the SELFE transport formulation, taking advantage of its numerical characteristics, such as the option to use different methods to solve the transport equation, while the remaining terms are computed based 

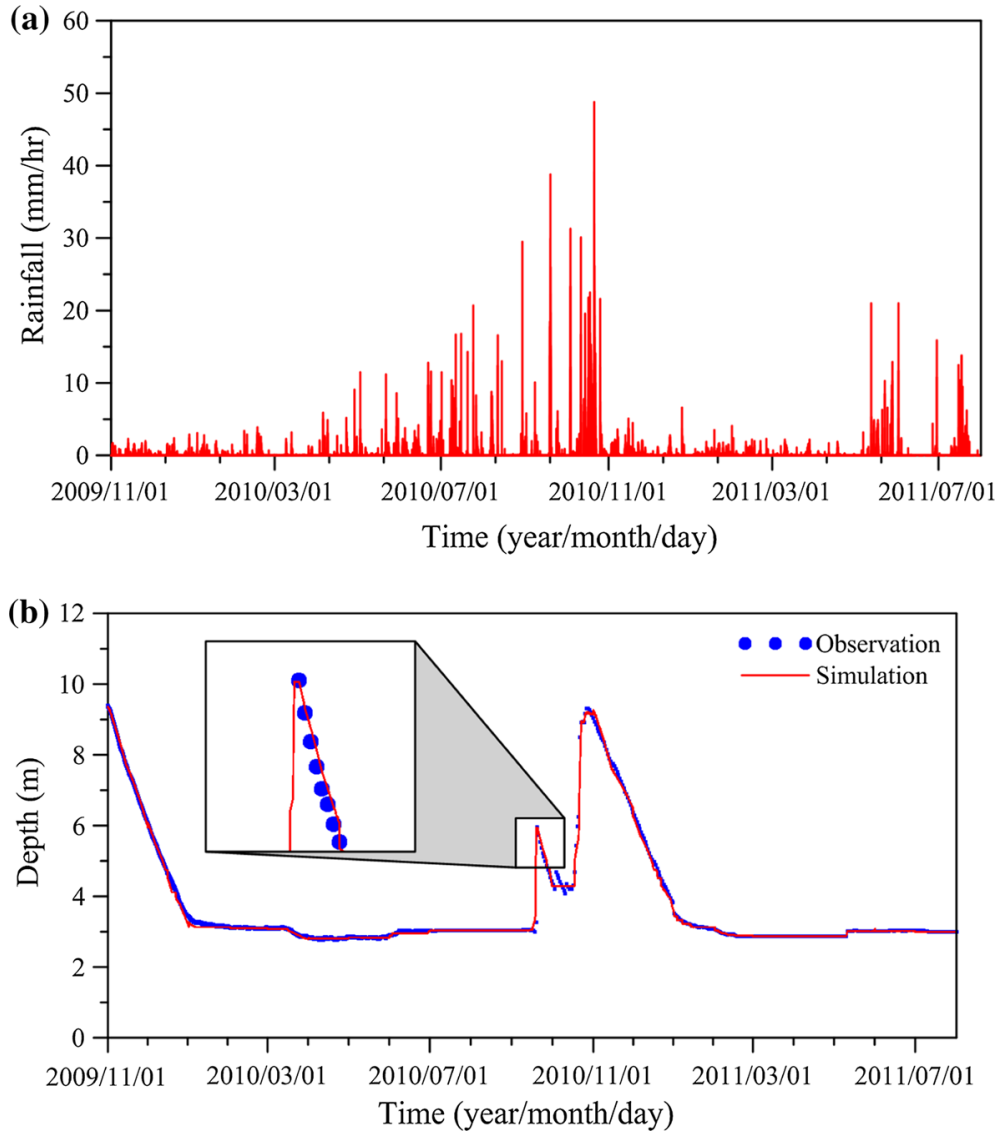

Figure 3. (a) Recorded rainfall from 1 November 2009 to 31 July 2011 and (b) comparison of water level between model prediction and observation.

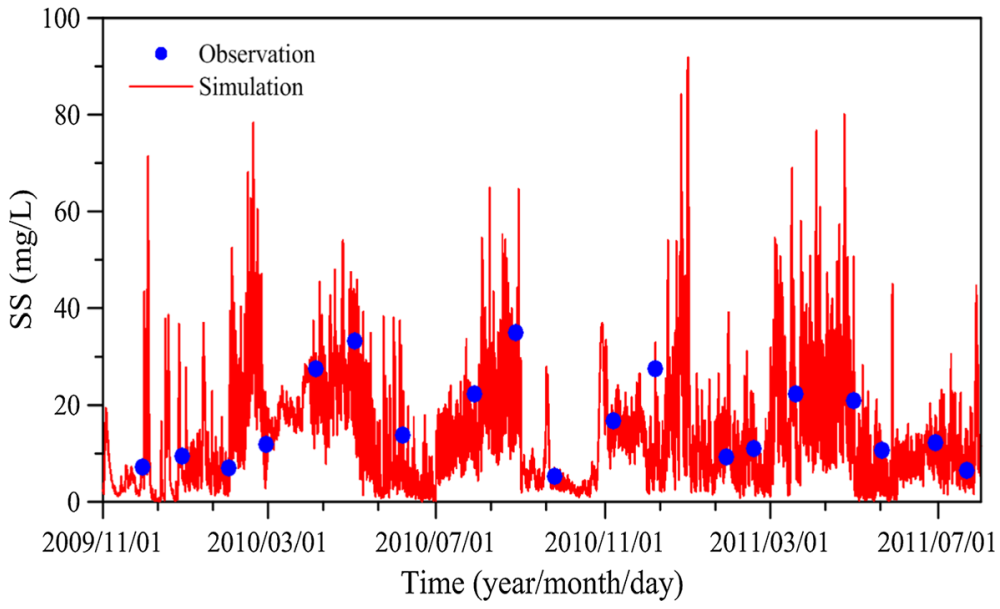

Figure 4. The comparison of suspended-sediment concentrations predicted by the model and measured at the buoy station from November 2009 to July 2011.

on the sediment transport formulation of a threedimensional hydrodynamic-eutrophication model (Lin and Kuo 2003).

The suspended-sediment transport model was incorporated using the hydrodynamic model as a passive tracer under the same spatial and temporal resolutions. The governing equation for the total suspended-sediment concentration is as follows (Lou et al. 2000):

$$
\begin{aligned}
& \frac{\partial C}{\partial t}+\frac{\partial(u C)}{\partial x}+\frac{\partial(v C)}{\partial y}+\frac{\partial\left[\left(w-w_{\mathrm{s}}\right) C\right]}{\partial z} \\
& =\frac{\partial}{\partial z}\left(\kappa \frac{\partial C}{\partial z}\right)+F_{\mathrm{s}}
\end{aligned}
$$



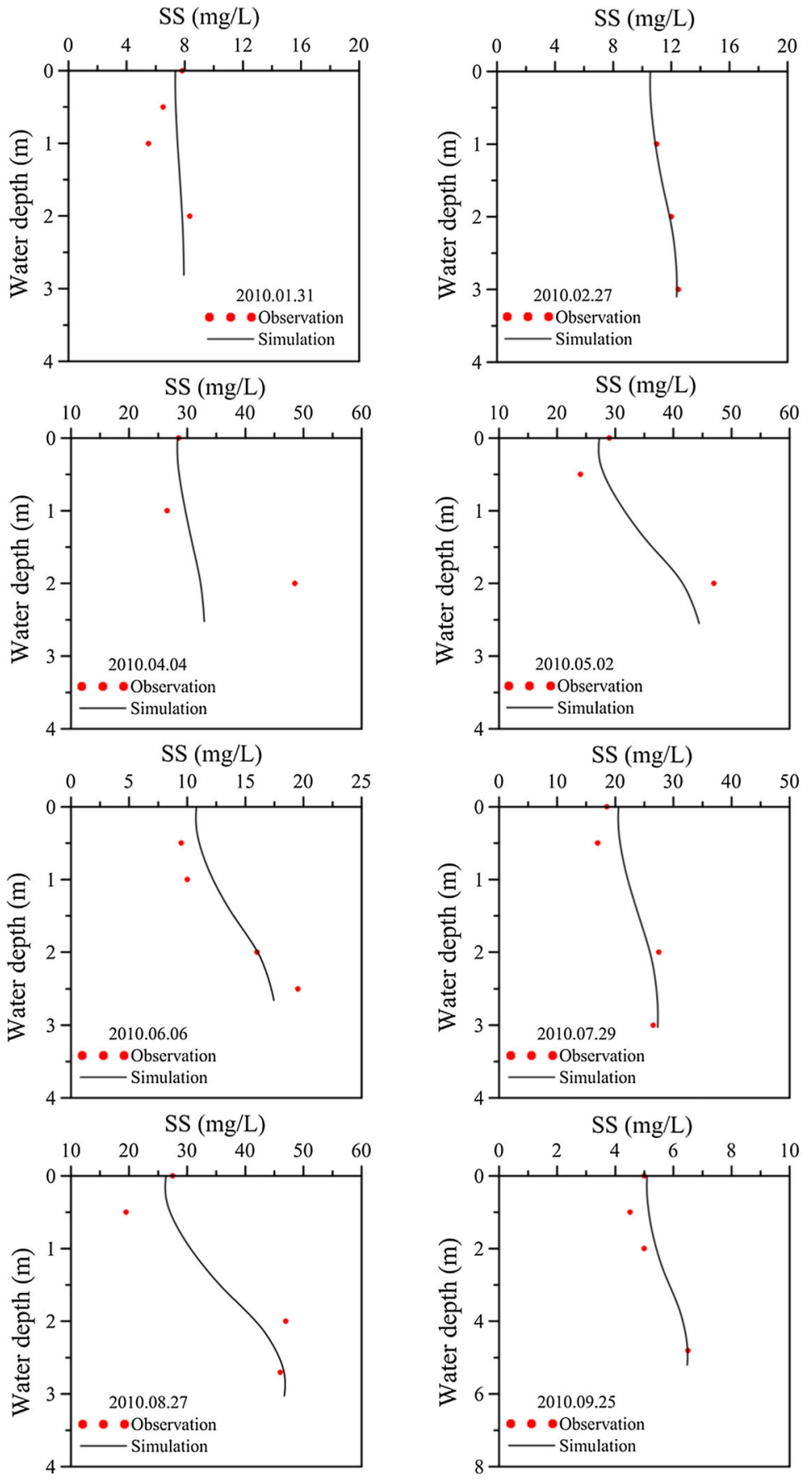

\section{$\mathrm{SS}(\mathrm{mg} / \mathrm{L})$}

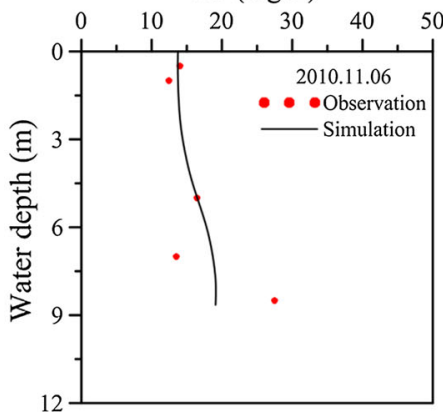

$\mathrm{SS}(\mathrm{mg} / \mathrm{L})$

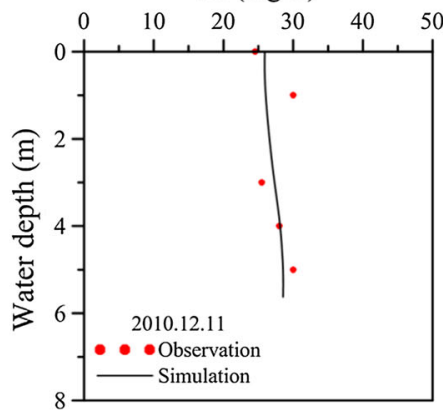

Figure 5. Comparison of vertical suspended-sediment profiles between model simulation and observation at the buoy station in 2010 . 

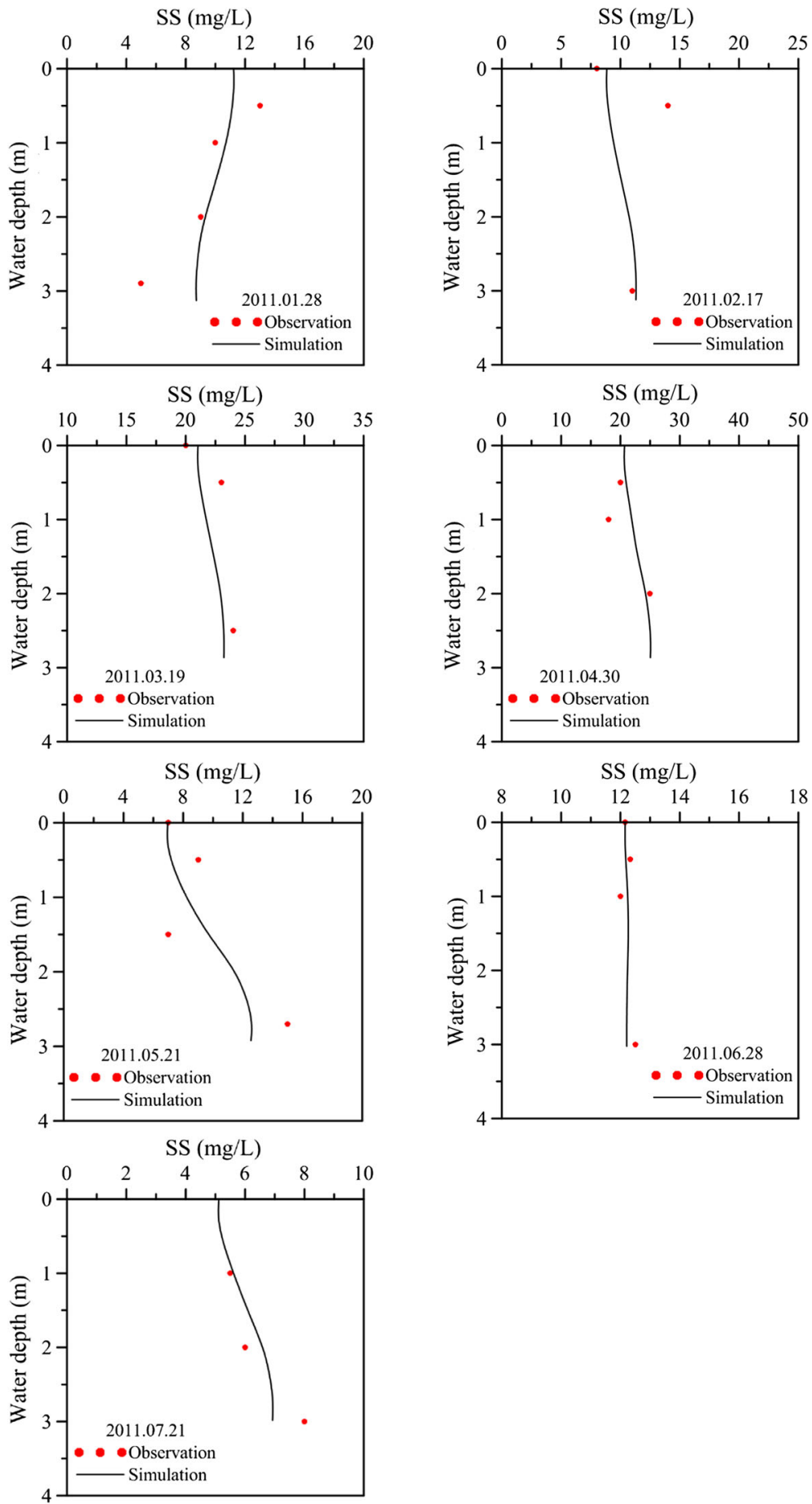

Figure 6. Comparison of vertical suspended-sediment profiles between model simulation and observation at the buoy station in 2011.

where $C$ denotes the suspended-sediment concentration; $u, v$ and $w$ are the velocity components in the $x, y$ and $z$ directions provided by SELFE, respectively; $w_{\mathrm{s}}$ is the settling velocity of the suspended sediment; $\kappa$ is the vertical eddy diffusivity; and $F_{\mathrm{s}}$ represents the horizontal diffusion.

At the water surface, there is no net transport across the free surface, and, therefore, diffusion flux always counterbalances the settling flux and the boundary condition (Jin and Ji 2004)

$$
w_{\mathrm{s}} C+\kappa \frac{\partial C}{\partial z}=0 \quad \text { at } z=\eta,
$$

where $\eta$ is the free-surface elevation. 
At the sediment bed, the net sediment flux is equal to the summation of the sediment erosion flux and the sediment deposition flux (Jin and Ji 2004):

$$
w_{\mathrm{s}} C+\kappa \frac{\partial C}{\partial z}=D-E \quad \text { at } z=-h .
$$

The erosion term $E\left(\mathrm{~kg} / \mathrm{m}^{2} / \mathrm{s}\right)$ is expressed according to the Partheniades (1965) formulation, using the excess-bottom shear-stress concept:

$$
E= \begin{cases}M\left(\frac{\tau_{\mathrm{b}}}{\tau_{\mathrm{ce}}}-1\right) & \text { for } \tau_{\mathrm{b}}>\tau_{\mathrm{ce}} \\ 0 & \text { for } \tau_{\mathrm{b}} \leq \tau_{\mathrm{ce}}\end{cases}
$$

where $\tau_{\mathrm{b}}$ is the bottom shear stress $\left(\mathrm{N} / \mathrm{m}^{2}\right), \tau_{\text {ce }}$ is the critical shear stress $\left(\mathrm{N} / \mathrm{m}^{2}\right)$ for erosion and $M$ is the erosion coefficient $\left(\mathrm{kg} / \mathrm{m}^{2} / \mathrm{s}\right)$.

The deposition term $D\left(\mathrm{~kg} / \mathrm{m}^{2} / \mathrm{s}\right)$ is calculated following the Krone (1962) formulation:

$$
D= \begin{cases}w_{\mathrm{s}} C_{\mathrm{b}}\left(1-\frac{\tau_{\mathrm{b}}}{\tau_{\mathrm{cd}}}\right) & \text { for } \tau_{\mathrm{cd}}>\tau_{\mathrm{b}} \\ 0 & \text { for } \tau_{\mathrm{cd}} \leq \tau_{\mathrm{b}}\end{cases}
$$

where $\tau_{\mathrm{cd}}$ is the critical shear stress $\left(\mathrm{N} / \mathrm{m}^{2}\right)$ for deposition and $C_{\mathrm{b}}$ is the near-bed SSC. For simulating the hydrodynamic properties such as density stratification and gravitationally driven flow, the effects of suspended-sediment concentration on density have to be considered. Water density including the suspended sediment was computed as follows (Chao et al. 2008):

$$
\rho=\rho_{\mathrm{w}}+C\left(1-\frac{\rho_{\mathrm{w}}}{\rho_{\mathrm{s}}}\right),
$$

where $\rho_{\mathrm{w}}$ is the water density, which is determined by the equation of state, and $\rho_{\mathrm{s}}$ is the suspendedsediment density.

The advection-diffusion component of sedimentsuspended transport model follows the SELFE transport formulation. The numerical description of the advective fluxes depends on the method used to solve the transport equation. The vertical advective fluxes are treated implicitly and the horizontal advective fluxes are treated explicitly using the finite-volume upwind method. The vertical diffusion term is treated implicitly and the concentration is computed at the prism centre.

\subsection{Model implementation}

In this study, the bottom topography data in the TFL measured in 2008 were obtained from the Academia Sinica, Taiwan. The greatest depth of study area is close to the buoy station that is $4.3 \mathrm{~m}$ (figure 1a). The unstructured model meshes for TFL consist of 11,617 meshes/6058 nodes in the horizontal direction (figure 1b). High-resolution unstructured meshes, which include a mesh size of approximately $5 \mathrm{~m}$, were used for TFL. The model simulations were conducted using 10 S-levels (i.e., $\sigma$-layers) in the vertical direction. The explicit treatment of the baroclinic term imposes the stability constraints for the grid size and time step. A stability condition for the baroclinic term in the model is given by $\left(\Delta t \sqrt{g h} / \Delta x_{x y}\right) \leq 1$, where $\Delta t$ is the time step, $g$ is the acceleration due to gravity, $h$ is the water depth and $\Delta x_{x y}$ is the grid size in the horizontal plane. For this model mesh, a time step $(\Delta t=20 \mathrm{~s})$ was used in simulations to guarantee the numerical stability.

\subsection{Indices of model performance}

To evaluate the performance of the hydrodynamic and suspended-sediment concentration, two criteria were adopted to compare the predicted

Table 1. Statistical error between simulated and measured suspended-sediment concentrations from November 2009 to July 2011.

\begin{tabular}{lcc}
\hline Year/month/date & $\begin{array}{c}\text { MAE } \\
(\mathrm{mg} / \mathrm{l})\end{array}$ & $\begin{array}{c}\text { RMSE } \\
(\mathrm{mg} / \mathrm{l})\end{array}$ \\
\hline $2009 / 11 / 29$ & 0.72 & 0.98 \\
$2009 / 12 / 28$ & 1.09 & 1.50 \\
$2010 / 01 / 31$ & 0.95 & 1.13 \\
$2010 / 02 / 27$ & 0.11 & 0.12 \\
$2010 / 04 / 04$ & 6.41 & 9.54 \\
$2010 / 05 / 02$ & 2.52 & 2.59 \\
$2010 / 06 / 06$ & 1.38 & 1.54 \\
$2010 / 07 / 29$ & 1.84 & 2.20 \\
$2010 / 08 / 27$ & 1.94 & 2.42 \\
$2010 / 09 / 25$ & 0.32 & 0.42 \\
$2010 / 11 / 06$ & 3.51 & 4.27 \\
$2010 / 12 / 11$ & 1.69 & 2.08 \\
$2011 / 01 / 28$ & 1.59 & 2.10 \\
$2011 / 02 / 17$ & 2.10 & 3.02 \\
$2011 / 03 / 19$ & 1.26 & 1.36 \\
$2011 / 04 / 30$ & 1.70 & 2.19 \\
$2011 / 05 / 21$ & 3.02 & 4.07 \\
$2011 / 06 / 28$ & 0.18 & 0.20 \\
$2011 / 07 / 21$ & 0.58 & 0.73 \\
\hline
\end{tabular}



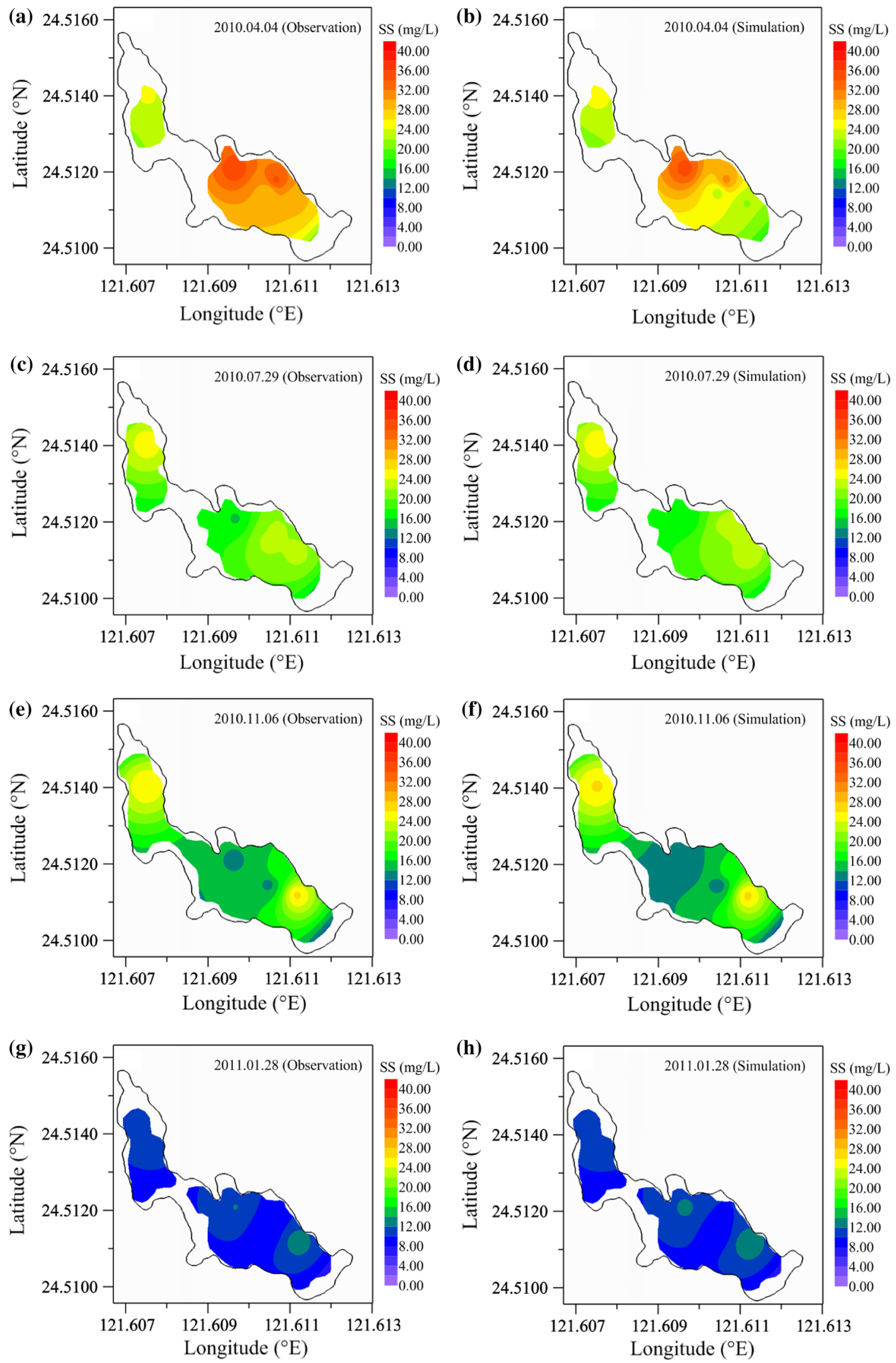

Figure 7. Comparison of spatial distributions of vertically averaged suspended-sediment concentration between model simulation and observation on 4 April, 29 July, 6 November 2010 and 28 January 2011. Note that figures (a) and (b) show the observation and simulation on 4 April 2010. Figures (c) and (d) present the observation and simulation on 29 July 2010. Figures (e) and (f) are the observation and simulation on 6 November 2010. Figures (g) and (h) present the observation and simulation on 28 January 2011. 

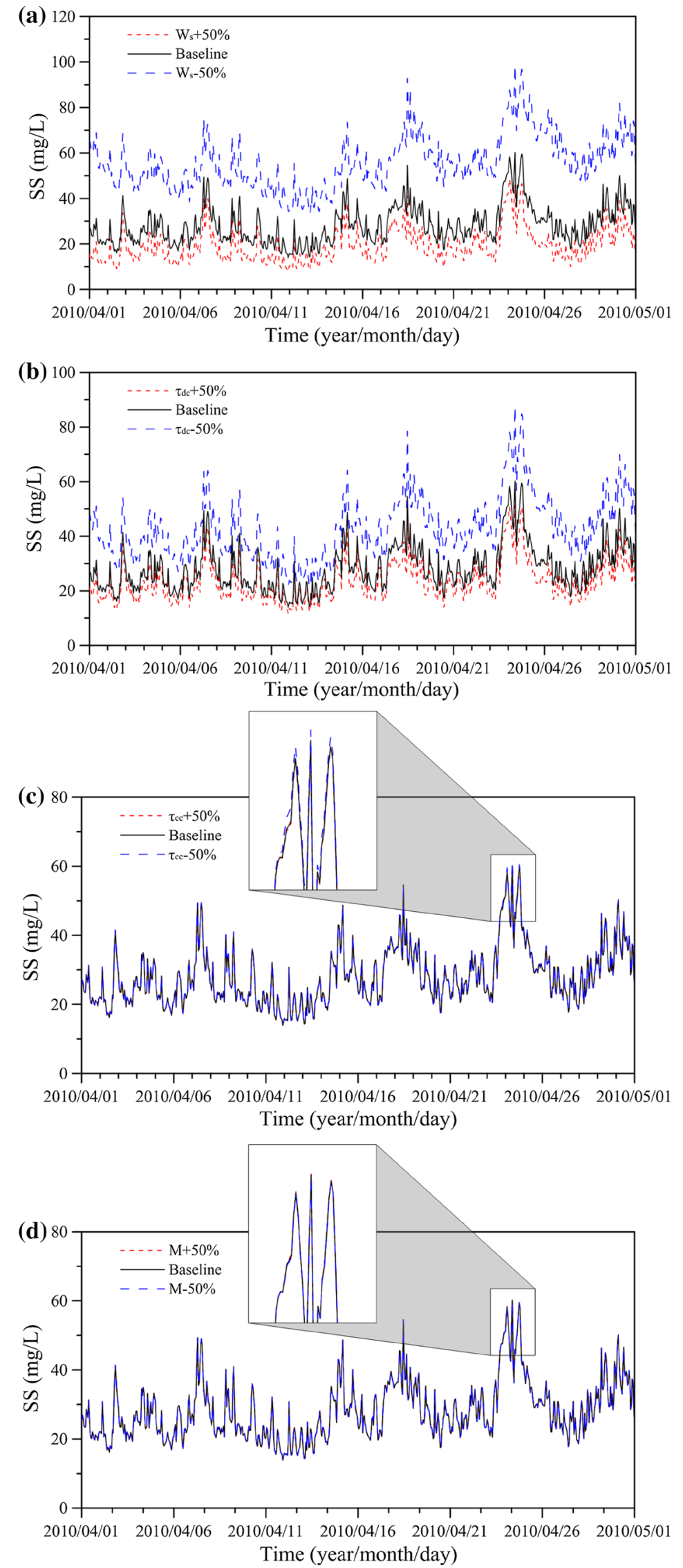

Figure 8. Model sensitivity for the $(\mathbf{a})$ settling velocity $\left(w_{\mathrm{s}}\right)$, (b) critical stress for deposition $\left(\tau_{\mathrm{dc}}\right)$, (c) critical stress for erosion $\left(\tau_{\mathrm{ec}}\right)$, and $(\mathbf{d})$ erosion rate constant $(M)$. 
results and the observational data, which are the mean absolute error (MAE) and root mean square error (RMSE). MAE is the average of the absolute values of differences between the observed data and simulated values. RMSE basically specifies the overall difference in the sum of squares normalised to the number of observations. RMSE is similar to a standard error of the mean for the uncertainty of the model. These criteria are defined by the following equations:

$$
\begin{aligned}
& \mathrm{MAE}=\frac{1}{N} \sum_{i=1}^{N}\left|\left(Y_{\mathrm{m}}\right)_{i}-\left(Y_{\mathrm{o}}\right)_{i}\right|, \\
& \mathrm{RMSE}=\sqrt{\frac{1}{N} \sum_{i=1}^{N}\left[\left(Y_{\mathrm{m}}\right)_{i}-\left(Y_{\mathrm{o}}\right)_{i}\right]^{2},}
\end{aligned}
$$

where $N$ is the total number of data points, $Y_{\mathrm{m}}$ is the modelled value and $Y_{\mathrm{o}}$ is the observational value.

\section{Model validation}

Simulation models are increasingly being used to solve problems and to aid in decision making. To make sure of the model accuracy for further practical applications, the observational data is used to validate the model and to ascertain its capability for predicting water level and suspendedsediment concentration (Thomann and Mueller 1987).

The observational data collected from November 2009 to July 2011 was used for model validation. To warm up the model, the spin-up time is specified as 15 days. The model was therefore run from 1 November 2009 to 31 July 2011. The initial conditions for water level and suspended-sediment concentration are specified as $3.0 \mathrm{~m}$ and $13.0 \mathrm{mg} / \mathrm{l}$, respectively, to start running the hydrodynamic and suspended-sediment transport model.

\subsection{Water level}

The daily discharge at the inflow and outflow locations and precipitation were served as input to calculate the water level for model validation. Figure 3(a) presents the recorded rainfall which reached $48.8 \mathrm{~mm} / \mathrm{h}$ on 21 October 2010 when Typhoon Megi hit Taiwan. The observed water levels in the TFL from 1 November 2009 to 31 July 2011 were compared with the model prediction shown in figure 3(b). The MAE and RMSE values between the computed and observed water surface elevations are 0.05 and $0.15 \mathrm{~m}$, respectively. It indicates that the simulated results mimic the observed water levels. Based on the model validation of water level, the roughness height used in the hydrodynamic model was adopted to be $0.01 \mathrm{~m}$ for the model simulation.

\subsection{Suspended-sediment modelling}

Several parameters in the suspended-sediment transport model including the settling velocity $\left(w_{\mathrm{s}}\right)$, critical stress for erosion $\left(\tau_{\mathrm{ce}}\right)$, deposition $\left(\tau_{\mathrm{cd}}\right)$ and empirical erosion rate $(M)$ are difficult to be determined in the lakes because they have a wide range of values to be adopted. The consolidation of the sediment bed affected by interactions with physical, biological, chemical and the composition of sediment is an important factor influencing these parameters (Liu 2005; Young and Ishiga 2014; Chen et al. 2015). Since these

Table 2. Results of model sensitivity run for four parameters.

\begin{tabular}{lcc}
\hline Parameter & Condition & $\begin{array}{c}\text { Maximum rate of } \\
\text { suspended-sediment } \\
\text { concentration }(\%)\end{array}$ \\
\hline Settling velocity $\left(w_{\mathrm{s}}\right)$ & $w_{\mathrm{s}}+50 \%$ & -43.85 \\
Critical stress for deposition $\left(\tau_{\mathrm{dc}}\right)$ & $w_{\mathrm{s}}-50 \%$ & 179.15 \\
& $\tau_{\mathrm{dc}}+50 \%$ & -24.31 \\
Critical stress for erosion $\left(\tau_{\mathrm{ec}}\right)$ & $\tau_{\mathrm{dc}}-50 \%$ & 90.27 \\
& $\tau_{\mathrm{ec}}+50 \%$ & -0.49 \\
Erosion rate $(M)$ & $\tau_{\mathrm{ec}}-50 \%$ & 2.80 \\
& $M+50 \%$ & 0.33 \\
& $M-50 \%$ & -0.33
\end{tabular}

Minus and plus represent decreasing and increasing suspended sediment concentrations, respectively. 
important parameters were not measured in the TFL, the suspended-sediment transport model is implemented to confirm these parameters.

In order to validate the suspended-sediment concentration in the TFL, the monthly measured data collected from November 2009 to July 2011 was compared with the simulated results. The water sample was taken from different water depths to measure the concentration of suspended sediment. Concentrations of suspended sediment were determined using the drying method after filtering samples through GF/F filters (APHA 1995). The comparison of the simulated suspended-sediment concentration and the measured concentration was taken as a vertical average at the buoy station is shown in figure 4 . It reveals that simulated results fairly match the measured suspended-sediment concentration. The MAE and RMSE values between the computed and measured suspendedsediment concentrations are 1.73 and $2.23 \mathrm{mg} / \mathrm{l}$, respectively.

Figures 5 and 6 present the vertical profiles of simulated and measured suspended-sediment concentrations at the buoy station in 2010 and 2011, respectively. It indicates that the model simulation results match the measured suspended-sediment concentrations in vertical profiles. Table 1 presents the statistical errors between simulated and measured suspended-sediment concentrations for each measured date from 2009 to 2011. It shows that the largest MAE and RMSE values are 6.41 and $9.54 \mathrm{mg} / \mathrm{l}$, respectively, occurring on 4 April 2010. The simulated suspended-sediment concentration underestimated the measured result at $2 \mathrm{~m}$ water depth. There may be two reasons for the underestimation. The first reason would be that the bed sediment was disturbed when the water sample was collected on 4 April 2010. The second reason would be that the measurement error of suspended-sediment concentration was measured in the laboratory. However, the uncertainty error of suspended-sediment concentration in the experimental measurements is about $\pm 4 \mathrm{mg} / \mathrm{l}$.

Figure 7 illustrates the comparison of the spatial distribution of the vertically averaged suspendedsediment concentration between simulated and observed results on 4 April, 29 July, 6 November 2010 and 28 January 2011. It can be seen that the simulated and observed suspended-sediment concentrations in their spatial distribution are
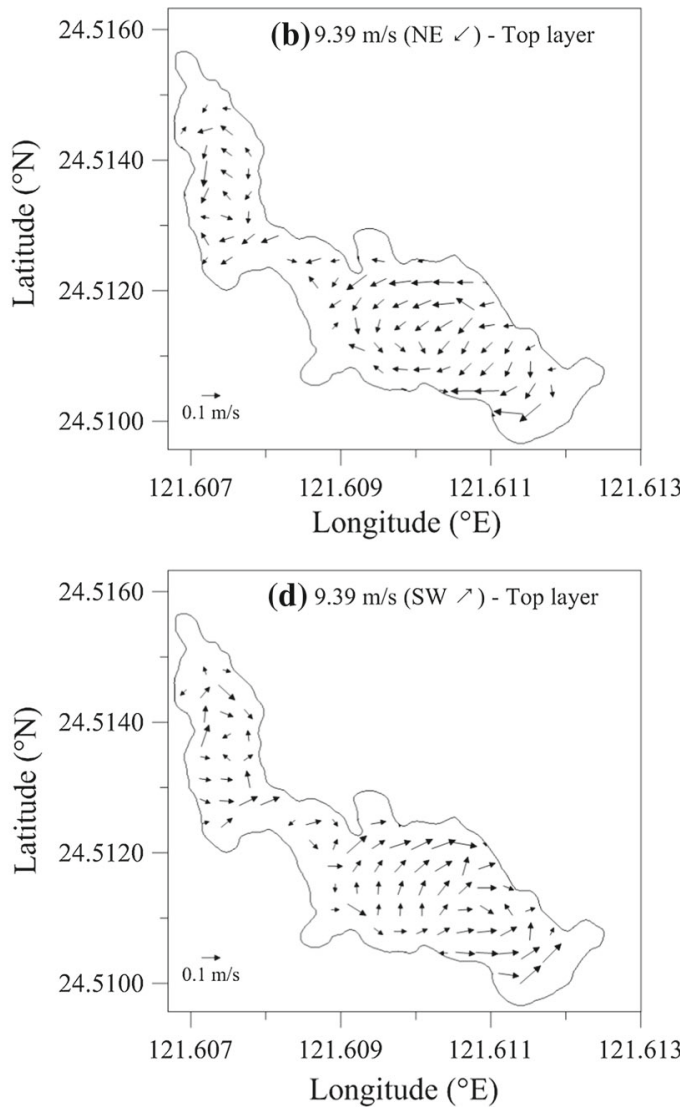

Figure 9. Mean circulation at the top layer for different wind speeds and directions: (a) northeast wind: $2.23 \mathrm{~m} / \mathrm{s}$; (b) northeast wind: $9.39 \mathrm{~m} / \mathrm{s}$; (c) northwest wind: $9.39 \mathrm{~m} / \mathrm{s}$; and (d) southwest wind: $9.39 \mathrm{~m} / \mathrm{s}$. 
quite similar. Through the model validation, the constant values of $1.0 \times 10^{-3} \mathrm{~m} / \mathrm{s}$ for settling velocity $\left(w_{\mathrm{s}}\right), 5.0 \times 10^{-3} \mathrm{~N} / \mathrm{m}^{2}$ for $\tau_{\text {ce }}, 5.0 \times$ $10^{-4} \mathrm{~N} / \mathrm{m}^{2}$ for $\tau_{\mathrm{cd}}$, and $5.0 \times 10^{-6} \mathrm{~kg} / \mathrm{m}^{2} / \mathrm{s}$ for $M$ were chosen for the suspended-sediment transport model. Jin and Ji (2004) used the model parameters of $1.0 \times 10^{-5} \mathrm{~m} / \mathrm{s}$ for $w_{\mathrm{s}}, 0.216 \mathrm{~N} / \mathrm{m}^{2}$ for $\tau_{\text {ce }}$, $0.18 \mathrm{~N} / \mathrm{m}^{2}$ for $\tau_{\text {cd }}$, and $5.0 \times 10^{-6} \mathrm{~kg} / \mathrm{m}^{2} / \mathrm{s}$ for $M$ in the Lake Okeechobee based on the model validation. Chao et al. (2008) used the parameters of $5.0 \times 10^{-3}-1.0 \times 10^{-2} \mathrm{~m} / \mathrm{s}$ for $w_{\mathrm{s}}, 0.02 \mathrm{~N} / \mathrm{m}^{2}$ for $\tau_{\text {ce }}, 0.01 \mathrm{~N} / \mathrm{m}^{2}$ for $\tau_{\text {cd }}$, and $1.0 \times 10^{-5} \mathrm{~kg} / \mathrm{m}^{2} / \mathrm{s}$ for $M$ in a shallow oxbow lake. Comparing with the parameters adopted in the literature, there were no consistent values for model parameters used in the sediment transport model.

\section{Model investigations and discussion}

\subsection{Model sensitivity analysis}

The sensitivity analysis is the study of how the uncertainty in the output of a mathematical model can be apportioned to different sources of uncertainty in its inputs. Three-dimensional suspended-sediment transport models have been applied to examine the sensitivity of their models to alter the physical forcing (Stanev et al. 2007; Wang et al. 2007; Warner et al. 2008). In this study, a model sensitivity analysis was implemented to explore the effects of settling velocity $\left(w_{\mathrm{s}}\right)$, the critical stress for erosion $\left(\tau_{\mathrm{ec}}\right)$, deposition $\left(\tau_{\mathrm{dc}}\right)$ and the empirical erosion rate $(M)$ on the suspended-sediment concentration and to determine the most important factor that affects the suspended-sediment concentration in the TFL.

The original bases depend on the simulation of model validation from 1 April 2010 to 30 April 2010. The effects of these parameters on the suspended-sediment concentration were investigated with two alternative cases; one involves the value used in model validation plus $50 \%$ and the other involves the value minus $50 \%$. Figure 8 presents the model sensitivity results for the four parameters during April 2010. It indicates that the settling velocity would be the most important parameter affecting the suspended-sediment concentration in the TFL. Table 2 lists the model
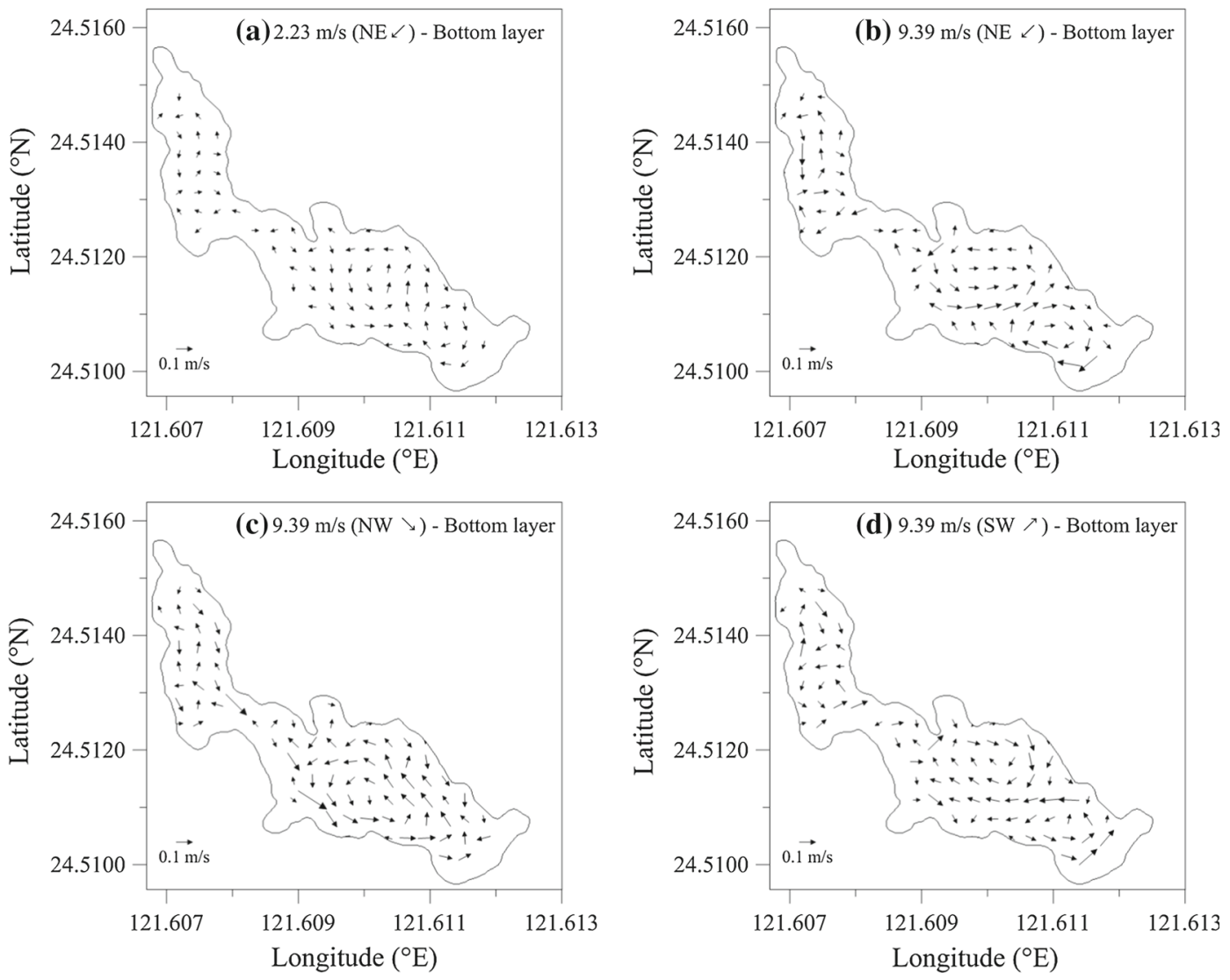

Figure 10. Mean circulation at the bottom layer for different wind speeds and directions: (a) northeast wind: $2.23 \mathrm{~m} / \mathrm{s}$; (b) northeast wind: $9.39 \mathrm{~m} / \mathrm{s}$; (c) northwest wind: $9.39 \mathrm{~m} / \mathrm{s}$; and (d) southwest wind: $9.39 \mathrm{~m} / \mathrm{s}$. 
sensitivity results. It indicates that an increase in settling velocity results in a decrease in the suspended-sediment concentration. The maximum rates for decreasing and increasing suspendedsediment concentrations are 43.85 and $179.15 \%$, respectively. The maximum rate (MR) means that the maximum values were determined by the formula represented by

$$
\mathrm{MR}=\frac{C_{\text {base }}-C_{\text {sens }}}{C_{\text {base }}} \times 100 \%
$$

where $C_{\text {base }}$ is the suspended-sediment concentration for the base runs shown in figure 4 and $C_{\text {sens }}$ is the suspended-sediment concentration for the sensitivity run shown in figure 8.

The most and least important factors to affect the suspended-sediment concentration are the settling velocity and the erosion rate, respectively, shown in table 2 based on model sensitivity runs. Lee et al. (2005) and Hawley et al. (2009) used a one-dimensional (vertical) resuspended bed model and a two-dimensional (vertical and cross-shore) sediment transport model, respectively, to implement model sensitivity to identify the important resuspension parameters in Lake Michigan. They found that the settling velocity was a crucial parameter in controlling the prediction of suspended-sediment concentration. Their simulated results of sensitivity analysis were similar to the current study with a three-dimensional suspendedsediment transport model. However, this study demonstrates that the erosion rate is the least important parameter in the suspended-sediment modelling.

\subsection{Influence of wind stress on current and suspended sediment}

The flows, surface waves and sediment resuspension in the shallow lakes are significantly driven by wind forcing (Kjaran et al. 2004; Kimura et al. 2014; Scheon et al. 2014). Podsetchine and Huttula (1994) addressed the correlation and time lag of wind direction/speed to resuspended sediment in the Lake Karhijärvi, Finland. Jin and Ji (2004)
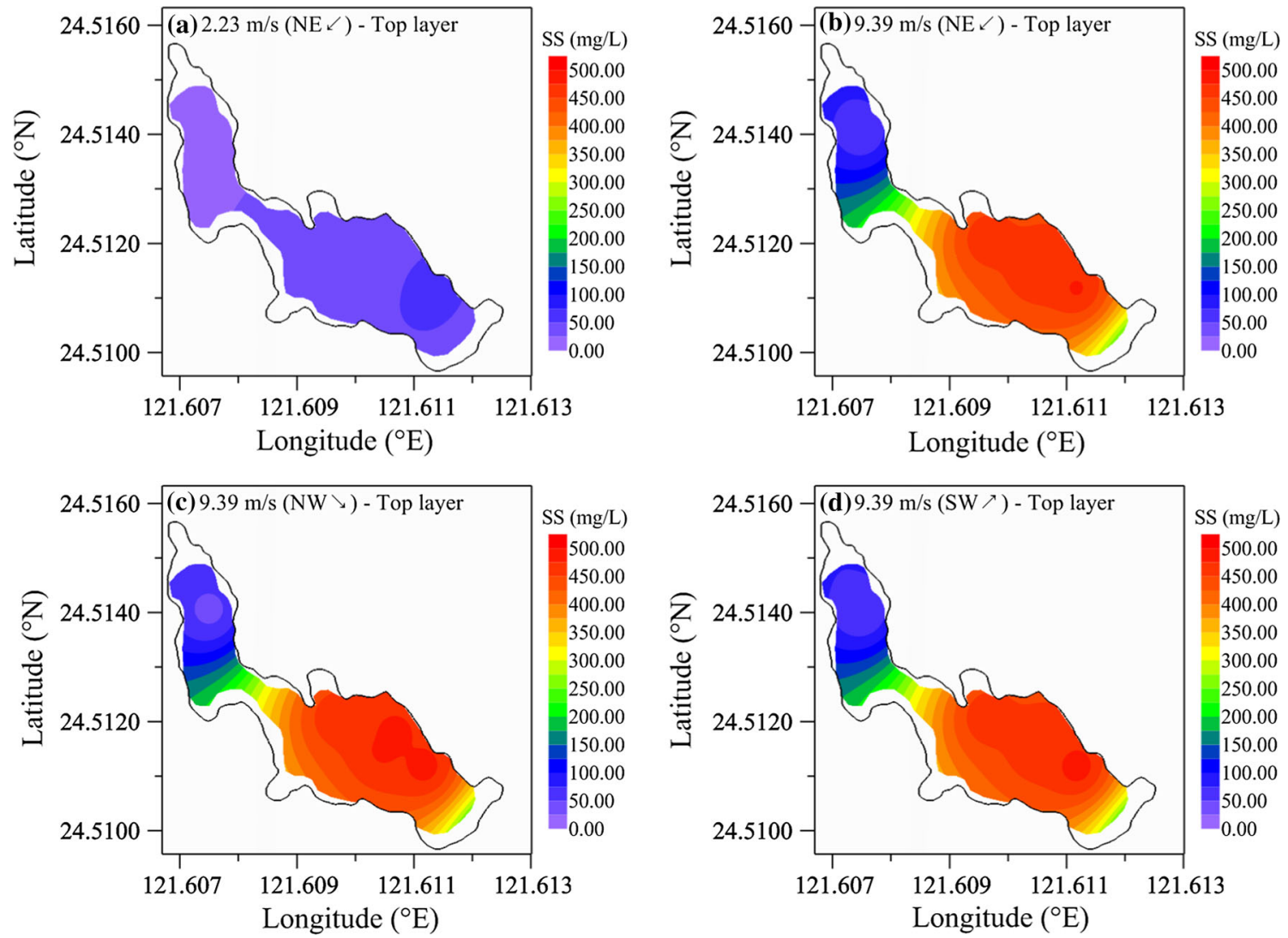

Figure 11. The distribution of mean suspended-sediment concentration in the top layer for different wind speeds and directions: (a) northeast wind: $2.23 \mathrm{~m} / \mathrm{s}$; (b) northeast wind: $9.39 \mathrm{~m} / \mathrm{s}$; (c) northwest wind: $9.39 \mathrm{~m} / \mathrm{s}$; and (d) southwest wind: $9.39 \mathrm{~m} / \mathrm{s}$. 
applied a three-dimensional model to investigate the effects of wind velocity and fetch and wind persistence on suspended-sediment concentrations in the Lake Okeechobee. The mean circulation in the TFL would be one of the important factors to affect the transport and distribution of suspended sediment. To investigate how the suspended sediment could be transported and distributed in the YYL, different wind speeds and directions including northeast wind: $2.23 \mathrm{~m} / \mathrm{s}$ (baseline), northeast wind: $9.39 \mathrm{~m} / \mathrm{s}$, northwest wind: $9.39 \mathrm{~m} / \mathrm{s}$ and southwest wind: $9.39 \mathrm{~m} / \mathrm{s}$ were used to drive the model simulation to yield mean circulation and suspended-sediment distribution. The wind speed and direction of $2.23 \mathrm{~m} / \mathrm{s}$ from the northeast in November 2010 were selected as a baseline. The maximum wind speed is $9.39 \mathrm{~m} / \mathrm{s}$ during the model validation period and prevailing wind directions are northeast, northwest and southwest adopted for model simulations to compare with the baseline condition.

The mean currents at the top and bottom layers for the baseline condition and for different wind speeds and directions, respectively, are shown in figures 9 and 10. The obvious anticyclonic circular gyre appears at the top layer for the baseline (figure 9a), while the cyclonic circular gyre is seen at the top layer for the southwest wind (figure 9d). Basically, the direction of the mean current at the top layer follows the wind direction. A strong wind results in high mean current at the top layer. The bottom currents are smaller than the surface currents. The mean surface currents are between 0.018 and $33.0 \mathrm{~cm} / \mathrm{s}$, while the mean bottom currents are between 0.01 and $31.1 \mathrm{~cm} / \mathrm{s}$.

Figures 11 and 12 show the distributions of suspended-sediment concentration at the top and bottom layers, respectively, for the baseline condition and for different wind speeds and directions. Both figures indicate that the distributions of suspended-sediment concentration are obviously different depending on the wind speed and direction. A strong wind produces high suspended-sediment concentrations in the surface and bottom layers. The highest concentration appears near the buoy station, while the lowest concentration appears at the outlet. The mean surface concentrations are between 19.0 and $489.7 \mathrm{mg} / \mathrm{l}$,
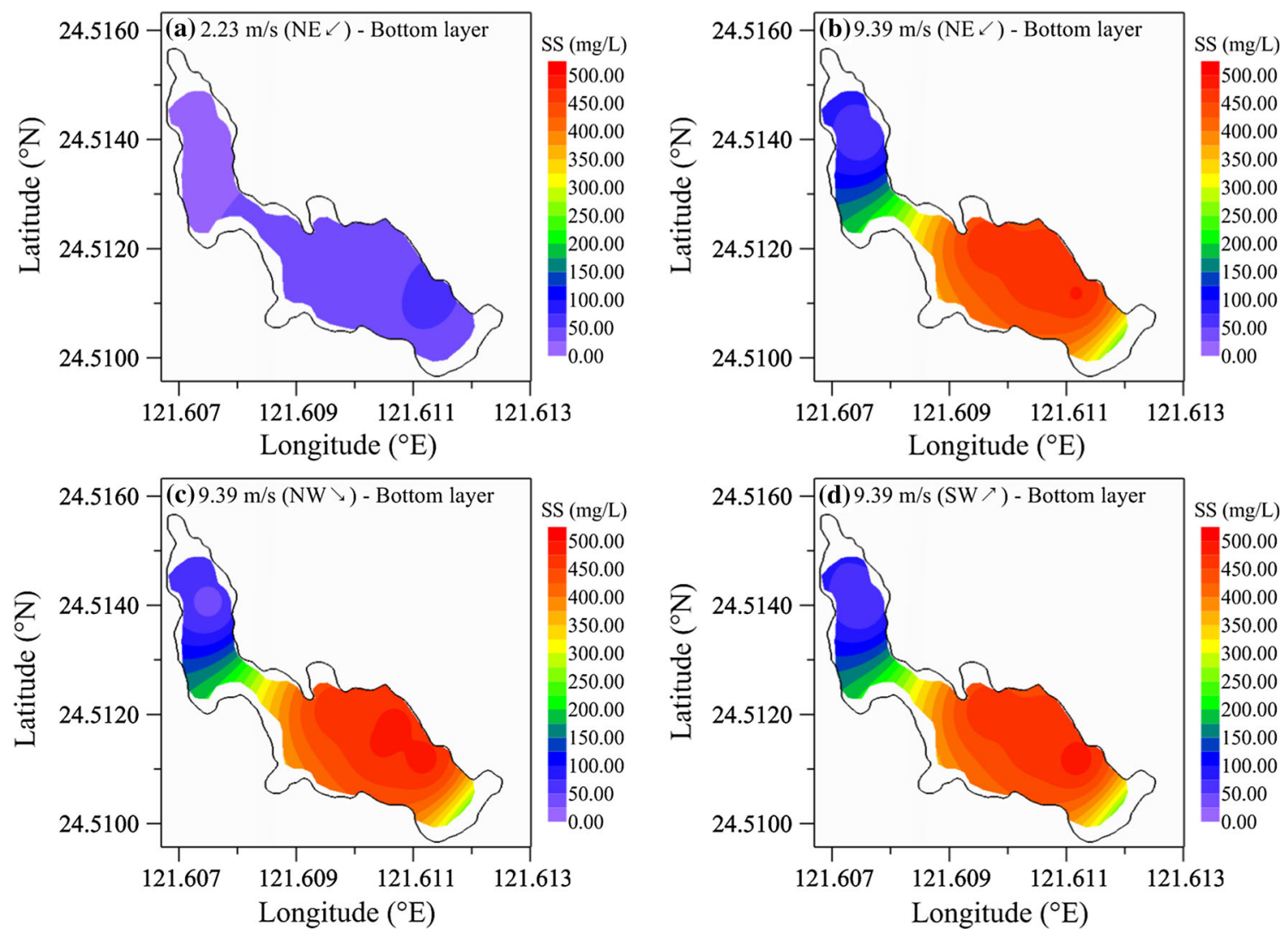

Figure 12. The distribution of mean suspended-sediment concentration at the bottom layer for different wind speeds and directions: (a) northeast wind: $2.23 \mathrm{~m} / \mathrm{s}$; (b) northeast wind: $9.39 \mathrm{~m} / \mathrm{s}$; (c) northwest wind: $9.39 \mathrm{~m} / \mathrm{s}$; and (d) southwest wind: $9.39 \mathrm{~m} / \mathrm{s}$. 

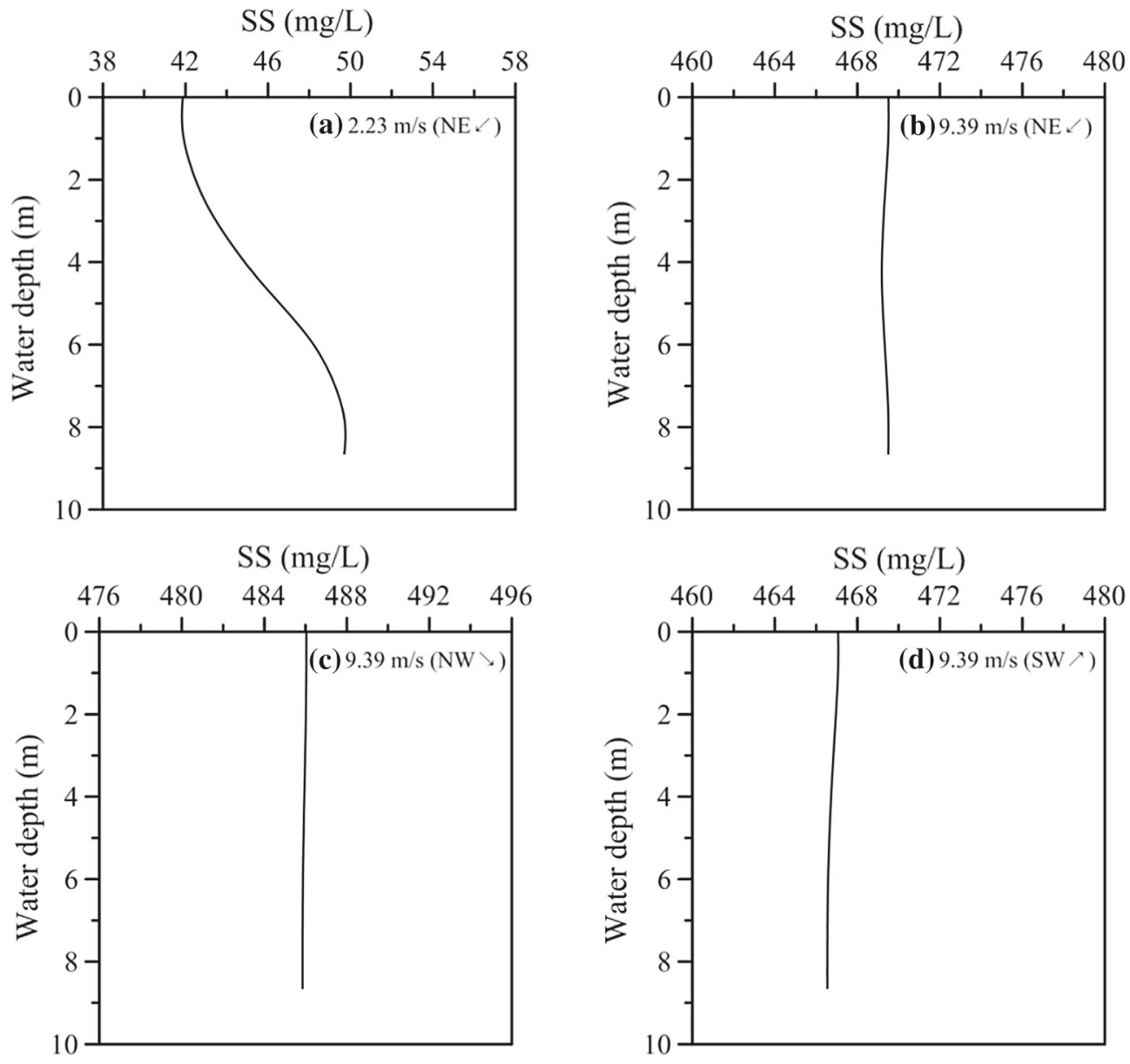

Figure 13. Vertical suspended-sediment profiles at the buoy station under different wind speeds and directions: (a) northeast wind: $2.23 \mathrm{~m} / \mathrm{s}$; (b) northeast wind: $9.39 \mathrm{~m} / \mathrm{s}$; (c) northwest wind: $9.39 \mathrm{~m} / \mathrm{s}$; and (d) southwest wind: $9.39 \mathrm{~m} / \mathrm{s}$.

while the mean bottom concentrations are between 19.4 and $491.9 \mathrm{mg} / \mathrm{l}$ for a wind speed of $9.39 \mathrm{~m} / \mathrm{s}$. These figures indicate that the spatial distribution of the suspended-sediment concentration was subject to wind speed. Figure 13 illustrates the simulated results of the vertical suspended-sediment profile at the buoy station under conditions of different wind speeds and directions. It shows that the suspended-sediment concentrations in the vertical direction are homogeneous under conditions of a northeast wind, northwest wind and a southwest wind at $9.39 \mathrm{~m} / \mathrm{s}$, while stratification occurred with a northeast wind at $2.23 \mathrm{~m} / \mathrm{s}$. The different wind speeds and directions also produced different patterns in the vertical suspendedsediment concentration. The northwest wind at $9.39 \mathrm{~m} / \mathrm{s}$ produces the highest suspended-sediment concentration at the buoy station (figure 12c). It implies that the water quality conditions in the lake may be affected by wind stress. Jin and Ji (2004) documented that the effects of windinduced current and wind-induced resuspension on suspended-sediment transport were important factors affecting the suspended-sediment concentration in Lake Okeechobee. Cozar et al. (2005) presented empirical correlations between turbidity and wind speed based on the field measurements. They yielded a formula and used the wind speed and water depth to calculate the suspendedsediment concentration. It meant that the strength of wind speed had a high relationship with the suspended-sediment concentration. This study substantially demonstrates that wind stresses have a significant influence on the mean circulation and suspended-sediment transport and distribution in a shallow lake.

\section{Conclusions}

A three-dimensional hydrodynamic and suspendedsediment transport model was developed and applied to the TSF in the north-central region of Taiwan. The model was validated with observed 
water level and suspended-sediment concentrations in 2009, 2010 and 2011. The predicted results quantitatively agreed with measured data in the lake.

The validated model was applied to investigate the important factor to affect the suspendedsediment distribution in the TFL. The model sensitivity analysis indicates that the settling velocity is the most important parameter affecting the suspended-sediment concentration and the erosion rate is the least important parameter in the suspended-sediment transport modelling. Therefore, this parameter (i.e., settling velocity) should be carefully adjusted when the model is used for the model validation procedure. The model was also used to probe the mean current and suspendedsediment distribution in the TFL. Wind speed and direction are the dominant factors driving the current patterns and affecting the suspendedsediment concentration. The obvious anticyclonic and cyclonic circular gyres appear in the lake based on the wind stress. The distributions of suspended-sediment concentration are clearly different depending on the wind speed and direction. Strong winds result in high mean currents and suspended-sediment concentrations in the top and bottom layers due to the effect of resuspension in a shallow lake.

\section{Acknowledgements}

This research was founded by the Academia Sinica, Taiwan (No. AS-103-TP-B15) and the Ministry of Science and Technology, Taiwan (MOST 105-2625M-865-002). The financial support was greatly appreciated. The authors also thank Dr. W.B. Chen of the National Science and Technology Centre for Disaster Reduction (NCDR), for providing the suspended-sediment transport model. The authors acknowledge anonymous reviewers for their useful comments and suggestions in improving the paper.

\section{References}

APHA 1995 Standard Methods for the Examination of Water and Wastewater; 19th edn, American Public Health Association, Washington, DC, USA.

Burban P Y, Xu Y J, Mcnell J and Lick W 1990 Settling speeds of flocs in fresh water and seawater; J. Geophys. Res. 95(C10) 18213-18220.

Cardenas M P, Schwab D J, Eadie B J, Hawley N and Lesht B M 2005 Sediment transport model validation in Lake Michigan; J. Great Lakes Res. 31(4) 373-385.
Chalov S R, Jarsjo J, Kasimov N S, Romanchenko A O, Pietron J, Thorslund J and Promakhova E V 2015 Spatio-temporal variation of sediment transport in the Selenga River Basin, Mongolia and Russia; Environ. Earth Sci. 73(2) 663-680.

Chao X, Jia Y, Shields Jr F D, Wang S S Y and Cooper C M 2007 Numerical modeling of water quality and sediment related processes; Ecol. Model. 201 385-297.

Chao X, Jia Y, Shields Jr F D, Wang S S Y and Cooper C M 2008 Three-dimensional numerical modeling of cohesive sediment transport and wind wave impact in a shallow oxbow lake; Adv. Water Resour. 31(7) 10041014

Chen W B, Liu W C, Hsu M H and Hwang C C 2015 Modelling investigation of suspended sediment in a tidal estuary using a three-dimensional model; Appl. Math. Model. 39(9) 2570-2586.

Cheng W Y 2010 Using water quality variables to establish light attenuation model in subtropic subalpine Yuan-Yang Lake and Tsuei-Feng Lake; Master thesis of Department of Civil and Disaster Prevention Engineering, National United University, Taiwan.

Chung E G, Bombardelli F A and Schladow S G 2009 Modeling linkages between sediment resuspension and water quality in a shallow, eutrophic, wind-exposed lake; Ecol. Model. 220 1251-1265.

Clarke G K C, Bush A B G and Bush J W M 2009 Freshwater discharge, sediment transport, and modeled climate impacts on the final discharge of glacial Lake Agassiz; J. Clim. 22(8) 2161-2180.

Cozar A, Galvez J A, Hull A, Garcia C M and Loiselle S A 2005 Sediment resuspension by wind in a shallow lake of Esteros del Ibera (Argentina): A model based on turbidimetry; Ecol. Model. 186 63-76.

DiToro D M 2001 Sediment Flux Modeling; Wiley \& Sons, Inc.

Filistovic V, Maceika E, Tarasiuk N, Lukisence B, Konstantinova M, Buivydas S, Koviazine E and Puzas A 2015 Model of non-equilibrium multiphase contaminant transport in lake water-sediment system; Water Air Soil Poll. 226(6) 202.

Gbah M B, Rao Y R and Murthy R C 2001 Turbulent exchange characteristics in the hypolimnion layer of Lake Ontario; Nordic Hydrol. 32(1) 13-28.

Hawley N, Harris C K, Lesht B M and Clites A H 2009 Sensitivity of a sediment transport model for Lake Michigan; J. Great Lakes Res. 35(4) 560-576.

Horne A J and Goldman C R 1994 Limnology; McGraw-Hill Higher Education.

Houwing E R and Rijn L C 1998 In situ erosion flume (ISEF): Determination of bed-shear stress and erosion of a kaolinite bed; J. Sea Res. 39(3) 243-253.

James R T, Martin J, Wool T and Wang P F 1997 A sediment resuspension and water quality model of lake Okeechobee; J. Am. Water Resour. As. 33(3) 661680.

Ji Z G, Hamrick J H and Pagenkopf J 2002 Sediment and metals in shallow river; J. Environ. Eng. ASCE 128(2) 105-119.

Jin K R and Ji Z G 2004 Case study: Modeling of sediment transport and wind-wave impact in lake Okeechobee; J. Hydraul. Eng. ASCE 130(11) 1055-1067. 
Kessarkar P M, Purnachandra R V, Shynu R, Ahmad I M, Mehra P, Michael G S and Sundar D 2009 Wind-driven estuarine turbidity maximum in Mandovi Estuary, central west coast of India; J. Earth Syst. Sci. 118369.

Kimura N, Liu W C, Chiu C Y and Kratz T K 2014 Assessing the effects of severe rainstorm-induced mixing on a subtropical, subalpine lake; Environ. Monit. Assess. 186 3091-3114.

Kjaran S P, Holm S L and Myer E M 2004 Lake circulation and sediment transport in lake Myvatn; Aquat. Ecol. 38(2) 145-162.

Krone R B 1962 Flume Studies on the Transport of Sediment in Estuarine Shoaling Processes, Hydraulic Engineering Laboratory, University of California, Berkeley.

Lee C, Schwab D J and Hawley N 2005 Sensitivity analysis of sediment resuspension parameters in coastal area of southern lake Michigan; J. Geophys. Res. 110 C03004.

Lee C, Schwab D J, Beletsky D, Stroud J and Lesht B 2007 Numerical modeling of mixed sediment resuspension, transport, and deposition during the March 1988 episodic events in southern lake Michigan; J. Geophys. Res. 112 C02018.

Li Y and Mehta A J 1998 Assessment of hindered settling of fluid mudlike suspensions; J. Hydraul. Eng. ASCE 124(2) 176-178.

Lin J and Kuo A Y 2003 A model study of turbidity maximum in the York River estuary, Virginia; Estuaries 26(5) 1269-1280.

Liu W C 2005 Modeling the influence of settling velocity on cohesive sediment transport in Tanshui river estuary; Environ. Geol. 47(4) 535-546.

Liu W C, Chan W T and Tsai D W 2016 Three-dimensional modeling of suspended sediment transport in a subalpine lake; Environ. Earth Sci. 75173.

Lou J, Schwab D J, Beletsky D and Hawley N 2000 A model of sediment resuspension and transport dynamics in southern Lake Michigan; J. Geophys. Res. 105(C3) 6591-6610.

Lv C, Zhang F, Liu Z, Hao S and Wu Z 2013 Threedimensional numerical simulation of sediment transport in lake Tai based on EFDC model; J. Food Agri. Environ. 11(2) 1343-1348.

Matty J M, Anderson J B and Dunbar R B 1987 Suspended sediment transport, sedimentation, and resuspension in lake Houston, Taxes: Implications for water quality; Environ. Geol. 10(3) 175-186.

Mehta A J and Partheniades E 1975 An investigation of the depositional properties of flocculated fine sediment; J. Hydraul. Res. 13(4) 361-381.

Mellor G L and Yamada T 1982 Development of a turbulence closure model for geophysical fluid problems; Rev. Geophys. 20(4) 851-875.

Partheniades E 1965 Erosion and deposition of cohesive soils; J. Hydraul. Div. ASCE 91(1) 105-139.

Podsetchine V and Huttula T 1994 Modeling sedimentation and resuspension in lake; Water Pollut. Res. J. Canada 29 309-342.

Pond S and Pickard G L 1998 Introductory Dynamical Oceanography; Butterworth-Heinemann.

Ramakrishnan R and Rajawat A S 2012 Simulation of suspended sediment transport initialized with satellite derived suspended sediment concentrations; J. Earth Syst. Sci. 121(5) 1201-1213.

Rodi W 1984 Turbulence Models and Their Applications in Hydraulics: A State of the Art Review; International Association for Hydraulics Research, Delft, The Netherlands.

Sanford L P 1992 New sedimentation, resuspension and burial; Limnol. Oceanogr. 37(6) 1164-1178.

Scheon J, Stretch D and Tirok K 2014 Wind-driven circulation patterns in shallow estuarine lake: St Lucia, South Africa; Estuar. Coast. Shelf Sci. 146 49-59.

Shchepetkin A F and Mcwilliam J C 2005 The regional oceanic modeling system (ROMS): A split-explicit, freesurface, topography-following-coordinate ocean model; Ocean. Model. 9(4) 347-404.

Stanev E V, Brink-Spalink G and Wolff J O 2007 Sediment dynamics in tidally dominated environments controlled by transport and turbulence: A case study for the East Frisian Wadden Sea; J. Geophys. Res. 112 C04018.

Stroud J R, Lesht B M, Schwab D J, Beletsky D and Stein M L 2009 Assimilation of satellite imagines into a sediment transport of Lake Michigan; Water Resour. Res. 45 W02419.

Thomann R V and Mueller J A 1987 Principles of Surface Water Quality Modeling and Control; Harper Collins Publishers, Inc., New York.

Thorn M F C 1981 Physical processes of siltation in tidal channels; In: Proceedings of Hydraulic Modelling Applied to Maritime Engineering Problems, ICE, London, pp. 4755.

Umlauf L and Buchard H 2003 A generic length-scale equation for geophysical turbulence models; J. Mar. Res. 61(2) 235-265.

Wang X H, Pinardi N and Malacic V 2007 Sediment transport and resuspension due to combined motion of wave and current in the northern Adriatic Sea during a Bora event in January 2001: A numerical study; Cont. Shelf Res. 27(5) 613-633.

Wang C, Shen C, Wang P F, Qian J, Hou J and Liu J J 2013 Modeling of sediment and heavy metal transport in Taihu lake, China; J. Hydrodyn. 25(3) 379-387.

Wang H, Zhang Z Z, Song D P, Zhou Y Y and Liu X D 2015 Water and sediment transport mechanisms in a larger liver-connected lake; Water Environ. J. 29(3) 391401.

Warner J C, Butman B and Dalyander P S 2008 Stormdriven sediment transport in Massachusetts Bay; Cont. Shelf Res. 28(2) 257-282.

Wilcox D C 1998 Reassessment of scale determining equation for advance turbulence models; AIAA J. 26(11) 1299 1310.

Young S M and Ishiga H 2014 Environmental change of the fluvial-estuary system in relation to Arase Dam removal of the Yatsushiro tidal flat, SW Kyushu, Japan; Environ. Earth Sci. 72(7) 2301-2314.

Zhang Y L and Baptista A M 2008 SELFE: A semi-implicit Eulerian-Lagrangian finite-element model for cross-scale ocean circulation; Ocean Model. 21(3-4) 71-96.

Zhang P, Chen X L, Lu J Z and Zhang W 2015 Assimilation of remote sensing observations into a sediment transport model of China's large freshwater lake: Spatial and 
temporal effects; Environ. Sci. Pollut. Res. 22(23) 18779 18792.

Ziegler C K and Nisbet B S 1995 Long-term simulation of fine-grained sediment transport in large reservoir; J. Hydraul. Eng. ASCE 121(11) 773-781.
Zouabi-Aloui B and Gueddari M 2014 Two-dimensional modelling of hydrodynamics and water quality of a stratified dam reservoir in the southern side of the Mediterranean Sea; Environ. Earth Sci. 72(8) 30373051 .

Corresponding editor: RAJIB MAITY 